\title{
The Actualization of Literary Learning Model Based on Verbal-Linguistic Intelligence
}

\author{
Nur Ihsan Hali*
}

FKIP, Universitas Sembilanbelas November Kolaka, Indonesia

Corresponding author: Nur Ihsan Hali, E-mail: nurihsanh101@gmail.com

\begin{tabular}{l} 
ARTICLE INFO \\
\hline Article history \\
Received: May 20, 2017 \\
Accepted: October 03, 2017 \\
Published: October 31, 2017 \\
Volume: $5 \quad$ Issue: 4 \\
\hline
\end{tabular}

Conflicts of interest: None Funding: None

\begin{abstract}
This article is inspired by Howard Gardner's concept of linguistic intelligence and also from some authors' previous writings. All of them became the authors' reference in developing ideas on constructing a literary learning model based on linguistic intelligence. The writing of this article is not done by collecting data empirically, but by developing and constructing an existing concept, namely the concept of linguistic intelligence, which is disseminated into a literaturebased learning of verbal-linguistic intelligence. The purpose of this paper is to answer the question of how to apply the literary learning model based on the verbal-linguistic intelligence. Then, regarding Gardner's concept, the author formulated a literary learning model based on the verbal-linguistic intelligence through a story-telling learning model with five steps namely arguing, discussing, interpreting, speaking, and writing about literary works. In short, the writer draw a conclusion that learning-based models of verbal-linguistic intelligence can be designed with attention into five components namely (1) definition, (2) characteristics, (3) teaching strategy, (4) final learning outcomes, and (5) figures.
\end{abstract}

Key words: Verbal-Linguistic Intelligence, Multiple Intelligences, Literary Learning Model

\section{INTRODUCTION}

Language or Verbal-Linguistic Intelligence is one kind of multiple intelligence which children have. Then, this verbal-linguistic intelligence is intelligence that is most frequently used in daily activities. In other words, verbal-linguistic intelligence is the intelligence which is associated with the ability to perform as well as to understand the information and communications from interlocutors, either in oral forms or in written forms. Every single person in this world agrees that the language becomes the most important thing in human life since they communicate with others by using a language either Indonesian, English, or any other languages that a person masters.

In Indonesia, the concept of multiple intelligences have not yet been optimally integrated in every level of education in schools. Moreover, they are an integral part in the management of education in developing countries. The implementation of multiple intelligence has just been done partially in a restricted educational environment. The implementation of multiple intelligence has just been done in the early childhood education, yet it was not handled professionally so the fundamental aspects of multiple intelligence might be ignored.

Here lies the importance of implementing the pillars of education as mandated by UNESCO, which includes (1) learning to know, (2) learning to do the job, (3) learning to live together, and (4) learning to be yourself (UNESCO,
2009). Regarding those pillars provided by UNESCO, some experts in Indonesia add one more pillar namely learning to serve (learning to worship) to the Almighty God. Those five pillars serve as the social asset to build the the whole Indonesian qualitatively who possess high intelligence and a noble personality so that they could develop themselves and other Indonesians who are civilized as well as democratic and also appreciate the national diversities or Bhineka Tunggal Ika.

The implementation of those pillars of education is closely related with learners' intelligence especially verbal linguistic intelligence. Some people believe that the verbal intelligence is nature. It means that it is a God's gift which is influenced by genetic inheritance and biological factors, and there is no intervention of human being. Meanwhile some other people believe that verbal intelligence is nurture. It means it can be taught. Children who have low verbal linguistic intelligence possibly can develop this intelligence through nurture process with the help of teachers. It is also applicable for children with high verbal linguistic intelligence. With the help of teachers, they could accelerate the development process of their verbal linguistic intelligence. This paper tries to offer a literary learning model based on verbal linguistic intelligence in order to foster their verbal linguistic development under the guide of this research question: how to apply the literary learning model based on the verbal-linguistic intelligence? 


\section{LITERATRUE REVIEW}

\section{Intelligence Diversity}

Gardner (1983) posited range intelligence is also influenced by the culture of the place where we were born so that intelligence is no longer interpreted as singular in cognitive discourse. According to Gardner (1993), it is a great mistake if we assume that IQ is an entity or a single quantity and keep it, which can be measured by using a pencil and paper. Gardner strengthens back his perspective on the definition of human cognitive intelligence and has demonstrated to us, how intelligence has a very broad spectrum, even Pierce dimensional emotionalities spiritualism, in which resides the ability of imagination, creativity, and problem solving. Gardner definition was a culture that was created from the process of learning, behavior, think this life pattern, and the natural environment of crystallized in the habit (custom). In other words, intelligence is a behavior that is repeated.

If so, that intelligence is a behavior that is done over and over again, then the question is why most of them who were described as a journalist/reporter, or a radio announcer, presenter, and news reporter on television do not have Bachelor educational background of communication studies or Bachelor of literature. Likewise, most of the employees at some banks are not from economic or accounting department, but their majors are agriculture or Informatics system. In fact, they are capable of assuming once received works, the process of training or apprenticeship carried out in a certain period of time. In the process of training and an internship that will happen later, learning will accumulate in the form of intelligence that has been standardized. Then, the next question is where is that intelligence come from? Maybe this question can be answered by saying that the human brain is a great source for many things. This question makes Hawkins and Blakeslee (2002) believe that real smart machines can be made by studying the human brain.

In addition, we have to know that the human brain is complex and mysterious, which stored personalities and intelligence. Intelligence is the grace of Almighty God. Through the scientific study of psychology, Garner (1993), who is also a neurologist at Harvard University, makes the classification of intelligence, based on empirical facts. Then, in 1999, he reproduced an intellectual work entitled Intelligence Reframed. He states that the human brain at least keeps nine kinds of intelligence that was agreed upon, while the rest are still a mystery, which consists of linguistic intelligence; logical-mathematical intelligence; spatial intelligence; kinesthetic intelligence; musical intelligence; interpersonal intelligence; intrapersonal intelligence; naturalist intelligence; and existentialist intelligence.

One of the nine intelligences that were pointed out by Gardner, is the linguistic quotient which is commonly called Vebal-Linguistic Intelligence. This type of intelligence then is associated with the study of literature that will be the focus of discussion in this paper.

In children lives, the role of language is very important in the effort to make the child's life more colorful. Even the language is seen as a social activity because children use their skills to build friendship, compromise, negotiate, and resolve problems. Language also plays an important role because it is always associated with various aspects of child development for children's emotional development and most beginners. The same activity is often done with a baby as well as smiling, flirting, and responding to parents, developing affection and emotional ties (Sonawat and Gogri, 2008, p. 20).

Another model of intelligence is proposed by McKenzie (2005). He proposes a new model of MI by elaborating Gardner's model of intelligence with the new needs of workplace in $21^{\text {st }}$ century. The model he proposes comprises of Information Technology Skills (the ability to access information and manipulate it by using various digital tools), Information Literacy Skills (the ability to evaluate validity and reliability of information using various critical thinking strategies), Problem-Solving Skills (the ability to generate effective and efficient solution to problems), Collaboration Skills (the ability to interact with people in society and working place), Flexibility (the ability to adapt and adjust ideas), and Creativity (ability to present information as well as ideas in new or creative ways). Those skills are corresponded with intelligence model of Gardner. Information technology skills are highly supported by kinesthetic intelligence. Information literacy skills are corresponded with intrapersonal and naturalist intelligences. The logical intelligence operates better in problem-solving skills. Interpersonal and verbal intelligences play an important role in collaboration skills. Musical intelligence is applicable in flexibility, and visual as well as existential intelligences have a great contribution in creativity.

\section{Linguistic Intelligence}

Later on, the definition of language according to van der Putten (2010) is as a communication tool which consists of words and is governed by a device and the convention, as well as identified by a group of users in a given geographic area referring to the users themselves. Thus, basically, language or linguistics (linguistic) cultures have social entity. I believe that almost the entire region in the archipelago has a language dialect and the intonation variety: ranging from traditional-sounding up and down sound, until the pitch which sounds like angry or barely inaudible because of the subtlety of the intonation. Mbok-mbok (an elder female) in Beringharjo market who is speaking with a Mekongganese (native peoples who inhabited the area of Mowewe, Watupute, Southeast Sulawesi) will be startled because the language intonation was rough and also the dialect was unknown by the elder. This situation is often described by a friend who came from Java. He said that we spoke with just two people, but it sounded like talking to five people. This condition may be influenced by the environment (the mountain and the sea) as well as the culture of the ancestors of the inhabitants which has happened since the nomadic period (not settled).

Every culture offers a taste of variety against the ability to use language such as Indonesia vernacular languages, Arabic, Chinese, French, Japan, English, and also language for sciences which require special ability to use it properly and correctly. 
In fact, not everyone is able to use it properly in conveying the ideas logically and also well structured, moreover in public. Those who have word power, the ability to arrange words, the ability to deliver speech in public, and the ability to write are considered to have potential of linguistic intelligence.

In children life, the role of language is very crucial in the effort to educate children's lives. Even language is seen as social activities; children use language skills to build friendships, compromise, negotiate, and solve problems encountered among them. Language also plays an important role because it is always associated with various aspects of child development and emotional development for the most novice children.

Gardner (1999) says that language is a special early example of human intelligence. It includes language intelligence process quality left brain and right brain, both in language within the meaning of linear and in a holistic sense. Language intelligence then appears to be a combination of various different systems such as expression of gestures, intonation, and cognitive ability to name and classify the sentence description. Thus, a child who has high language intelligence will be able to talk well, to make a funny joke, to write better than other average children who are in the same age with him, to have good memory of remembering names, places, dates, and other information than children in general, to like word games, to like reading a book, to appreciate poetry and word games, like to hear the story without looking at books, to communicate thoughts, feelings, and a good ideas, to listen and respond to sounds, rhythms, color, variety of spoken words (Lane, 2009, p. 3).

Kwok-Cheung, (2009, p. 10) views that a child who possesses a language more than other kids likes to imitate the sounds of the language, read and write, learn to listen, read, write and discuss, listen effectively, understand, summarize, interpret, explain new work by writing or oral penchant communication. They also often ask many questions, happy to talk, have a lot of vocabulary, love to read and write, understand the function of language, and be able to speak about language skills. To add, this intelligence considered very valuable in the learning process because it matches the traditional ways of teaching in the classroom. Thus verbal-linguistic intelligence becomes one of the most highly important intelligences in the classroom (McKenzie, 2005).

Linguistic intelligence includes (1) phonology, namely the ability of learners in issuing, imitating, or using the language sounds, (2) morphology, the ability of learners to acquire vocabulary, choose a vocabulary word that is appropriate, and develop it into a combination of morpheme and word, (3) syntax, the ability of learners in arranging acceptable phrases, clauses, and sentences, either a simple sentence which consists of only one subject and one predicate, and also in forming complex sentences with correct language structure, including the ability to arrange simple essay in a discourse with elements of cohesion and coherence in constructing ideas. In addition, he is also able to produce formal language. Language aptitude also has a close relationship to social aspects such as sociolinguistics and psycholinguistics.

\section{Characteristics of Children who have Verbal-Linguistic Intelligence}

The education process of teaching verbal-linguistic is a difficult to train. Thus this process should be done for children at the active age in their childhood. Sometimes parents are afraid of when their child is actively wandering around, so they prohibit their child to move where s/he wants. This will make the child's development in making progressive movement stop because of the fear of their parents.

Based on the concept of verbal-linguistic intelligence that has been discussed before, it can be concluded that Verbal-Linguistic intelligence is closely related to language skills and in their use. People who are gifted in art like playing with language, like reading and writing, is easy to be attracted by the sound, meaning and a story or narrative. They are often good spellers and easy to remember steps of procedures, places and names. In addition, there are some other characteristics related to children who have verbal-linguistic intelligence, namely:

1. being able to write their daily experiences

2. being able to explain their ideas better than children at their age,

3. being able to produce a lot of vocabularies and also use it appropriately than children at their age,

4. reading a lot of books, newspapers, magazines, articles on internet, and many others; frequently giving their thoughts, feedback, and criticism to others,

5. good at spelling foreign and new words correctly,

6. enjoying to hear oral statements (stories, reviews radio, voice books), like rhymes, puns, a set of words which are difficult to pronounce,

7. being able to talk at length or being able to tell jokes and stories.

They are very skillful to play on words. People who have this intelligence have the ability to compose his thoughts clearly. They are also able to express thoughts in the form of words such as speaking and writing. People with verbal intelligence is very proficient in language, telling stories, arguing, discussing, interpreting, submitting reports and other activities related to speaking and writing. This intelligence is required in the profession of a lawyer, writer, broadcaster/ television, editor, teacher, etc. Those who have this intelligence are John F Kennedy, Bung Karno (The first president of Indonesia), Kak Seto, and many other world leaders who have the verbal-linguistic intelligence.

Logical thinking intelligence of children can be shown on the intelligence of the language that they have. Children who are able to speak well and smoothly, might have a good logical thinking.

In daily life, kids tend to frequently use disordered words or they mix their traditional language with Indonesian. Therefore, children often incorrectly use the words especially for those who are exposure to bilingualism in their early age. To overcome and to stimulate children's verbal linguistic-intelligence, we can take the following ways:

1. frequently invite children to converse;

2. frequently read stories/fables;

3. frequently teach singing songs. 
Being able to speak does not only mean to master many languages, but also possess the ability to process language. Therefore, it is very important to teach the mother tongue in advance to improve the development of children logical thinking. Not all children are smart and ready to speak language. For instance, if a child is not ready to accept multi-language, then you do not need to for him to start learning a new language. When parents force children to learn multiple languages, it may make the child get confused in language experience or even he will get stressful.

It should also be realized that the environment is a big influence on the ability of a child's brain, which in turn, will affect the skill in processing words and speaking. Lack of communication in their childhood will lead to the lack of language skills of children. This also will make them reserved.

Meanwhile, Gardner (2001, p. 342) describes the characteristics of people who have the verbal-linguistic intelligence as follows: sensitive to patterns, neat, systematic, good at arguing, like listening, love reading and writing, easy to spell, love to play the words, good memories about trivial things, and being a reliable public speaker and debater.

Therefore, verbal-linguistic intelligence includes language skills of listening, reading effectively, speech, and writing. People who quickly capture oral and written information can be considered to be linguistically intelligent although they may be not really good at talking or writing (producing language). Verbal-linguistic intelligence has several indicators or special traits of intelligence. This intelligence includes the sensitivity of sound, structure, meaning, function words, and language. Individuals who have this intelligence tend to:

1. be happy and effective in communication in both verbal and written forms,

2. be good at making up stories,

3. be open to discuss and follow debates on certain issues,

4. enjoy learning foreign languages,

5. like playing language games, such as the sound game, and are sensitive to humor that arises as a result of the exchange of sound,

6. like reading and can uncover the meaning behind words,

7. remember quotations, statements from experts and specialists easily,

8. spell words accurately,

9. be good at making jokes by associating serious facts with similar facts which are not directly related causing amusement,

10. compose poems.

11. be sensitive to the structure and seldom make mistakes in forming sentences,

12. have a wide range of vocabulary and use a variety of words to describe something clearly, and

13. write clearly so that the reader is able to understand what they write easily.

For children, verbal-linguistic intelligence can emerge by doing various activities. Verbally intelligent children:

1. aged 2-6 love to communicate with other people, both with peers and adults;
2. aged 3-6 love to talk at length about their everyday experiences;

3. aged 2-6 easily remember the names of friends and family members, places or trivial things that they have heard or seen, including advertisement;

4. aged 2-4 love to carry a book and pretend to read it;

5. spell more quickly than children at their age (4-6 years);

6. aged 3-6 find it easy to play with words and like puns and humor;

7. aged 2-6 love and pay great attention to stories or reading stories from teachers;

8. aged 4-6 can retell story well;

9. aged 3-6 have a vocabulary range that exceeds most of the children at their age;

10. like to mimic inscription and show the achievement to children of their age;

11. aged 4-6 are able to make linear repetition, random letters, and write with a sound or phonetic spelling (Kindergarten Junior Students Class)and write the correct spelling portion (Kindergarten Senior Students Class);

12. love to read the writing on the labels of food-electronics, signs, store-house, the titles, and the like; and

13. enjoy language games, such as guessing words, random letters, jumbled sentences, and filling in the pieces of the story being told.

This article is based on the concepts and thoughts on Howard Gardner (1993). According to him, every person or child is born with intelligence. The human brain is complex and mysterious, in which personality and intelligence are stored. To add, intelligence is God's gift. In his work entitled Intelligence Reframed, Gardner (1999) states that the human brain keeps at least nine types of intelligences that are agreed upon, while the rest is still mysterious. The nine types of intelligence are (1) linguistic intelligence, (2) logical-mathematical intelligence, (3) spatial intelligence, (4) kinesthetic intelligence, (5) musical intelligence, (6) interpersonal intelligence, (7) intrapersonal intelligence, (8) naturalist intelligence, and (9) existentialist intelligence.

Linguistic intelligence as one of the nine intelligences that have been proposed will be the focus in this literature study. Focusing on Verbal-Linguistic Intelligence, the author will construct a learning design model that includes definitions, characteristics, teaching strategies, the best expected learning outcomes, and the characters playing the role of creating their works. The author built a concept, namely teaching strategy activities and the expected learning outcomes. In teaching strategy activities, writing an information and writing a script as the examples can create the best ending learning outcomes such as short story writers, literati, poetry readers, novelist, and book writers.

Howard Gardner's concept of linguistic intelligence and some of the theories that have been reviewed in the previous section became the writer's reference in developing this idea. Then, the writer also will try to construct a literary learning model which is developed on the basis of the potential of linguistic intelligence. In this article the term verbal-linguistic intelligence was used. The writing of this article was not done by collecting data empirically, but by developing and 
constructing an existing concept, namely the concept of linguistic intelligence.

\section{ACTIVITIES DEVELOPING VERBAL INTELLIGENCE}

There are several models of learning verbal-linguistic intelligence that can be developed through the study of literature. The models are (a) telling a story, (b) arguing, (c) discussion, (d) interpreting, (e) submitting a report, and (f) speaking and writing about literature.

There are five components that are linked to each other of verbal-linguistic intelengence. These components are definitions, characteristic, learning strategies, the best final learning outcomes, and the figures. Here we are going to discuss every component in detail.

At first, definition refers to describing the ability to think in terms of words, which use language to express, and appreciate complex meanings. This component is a general goal or basic competence to be achieved by the learner. Learners are targeted to have the ability to conceptualize ideas in the form of words, to express, and to communicate, and also able to appreciate the complex meaning experienced by the learners in their life.

Secondly, characteristics refer to the basic competencies to be achieved at the end of each lesson. Characteristics to be achieved in this section include four language skills, namely listening skills; speaking skills; reading skills; and writing skills. Furthermore, each language skill is operationalized as follows. Listening skills cover responding to the sound of rhythm, the color of the various phrases of words, imitating sounds of language, reading, and writing from others. The next is speaking skills. They cover speaking effectively to various audiences with different goals, and knowing how to make small talk, eloquent, persuasive and passionate at the right time and place. In addition, the learners are also expected to master other languages. The third is reading skills. They cover understanding, summarizing, interpreting or explaining, and remembering what has been read. Lastly, writing skills cover writing effectively, understanding and applying the rules of language, spelling, punctuation, and using effective vocabulary. The end of the character component is a standard character that is a combination of language skills, namely listening, speaking, reading, and writing. The standard characters are operationalized as follows: using listening, speaking, reading, and writing skills to remember, discuss, influence, create knowledge, construct meanings, and describe the language itself.

The third is learning strategies. The learning strategies are the means chosen to deliver learning materials in a particular learning environment. Further, it is described by them that the learning strategy includes; nature, scope, and sequence of learning activities that can provide learning experiences to learners. The chosen learning strategies chosen are learning strategies related to language skills formulated in operational words as follows: e.g. writing a script, writing information, interviewing, presentation, questioning, debating, interviewing, guessing, reporting an event and so forth.

The fourth is the final learning outcomes. It is the achievement of the ultimate goal of learning strategies that make learners who have good character and professionalism in every profession that learners are interest in. The expected learning outcomes are likely to exist in the following professions: writer, short story writer, screenwriter, poet, author, journalist, editor, orator, speaker, teacher/lecturer, lawyer, newsreader, translator, comedian, negotiator, storyteller, novelist, etc.

The last one is characters. In this part, the researcher will mention a list of names of successful leaders in various professions who is believed to provide a stimulus in literary learning. The list of national and international figures are the figures who have succeeded in their respective professions. The belief is certainly reasonable, because almost everyone idolizes or has an idol in accordance with their profession and intelligence. Some successful figures in politics and government, are the first president of the Republic of Indonesia Soekarno, until the current president of the Republic of Indonesia namely Joko Widodo. The characters of other professions are Andrea Hirata (novelist), Adnan Buyung Nasution (lawyer), and other characters who will inspire the learner to do the best as the idolized figure.

Furthermore, verbal-linguistic intelligence is a learning model that can help teachers design activities strategies such as debating, discussing, interpreting, relaying reports, speaking and writing (Figure 1). The application of such activities allows the learners to achieve the best possible learning outcomes which qualify the minimal standard of competency to be attained by the end of the course based on the verbal-linguistic learning model. Such activities prepare learners for their future professions as authors, presenters, negotiators, journalists, editors, orators as well as other professions. The following simple chart portrays some activities that can develop verbal linguistic intelligence.

Retelling a stories that have been read or heard by students in literary works, such as fairy tales, plays, novels, poems or ballads can develop their linguistic intelligence. Students can be prompted to tell stories following the steps below:

1. Students are required to listen or to read the literature that has been prepared by teachers.

2. Students note down the main points of the story being heard or being read.

3. Students retell the story that they have read or heard either orally or in the written form.

While applying these steps, the teacher will have to bear in mind that the literary work should be in accordance with students' cognitive development and it would be better if the literary works are localized. Stories which indirectly preserve the values and local culture in terms of both content

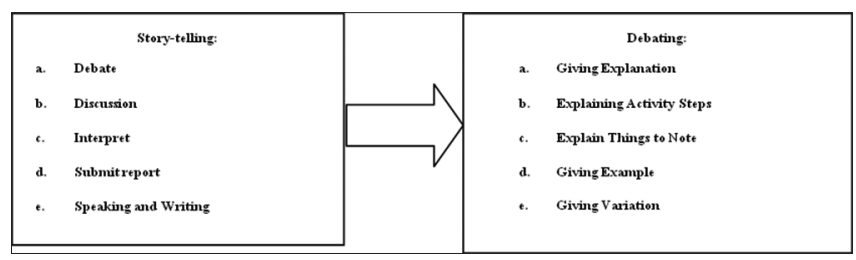

Figure 1. Learning Activities 
and language will be particularly appealing to learners. Finally, time allotment should be appropriate to the type of the story to be retold. What follows is an example of an activity:

1. Read a folklore of Southeast Sulawesi entitled "Larumbalangi".

2. Write down the main points of the story which you have just read.

3. Recount the story in writing by focusing on the main points.

Another alternative activity would be:

1. The teacher reads a fairy tale to students.

2. The teacher reads fairytale which is not too long, but still reflects the integrity of the story.

3. While listening to the tale read by the teacher, students note down the main points of the story.

Later on, the learners' verbal-linguistic intelligence can further be developed through the study of literature by maintaining an opinion on events, behaviors, or other phenomena contained in literary works which are read or heard. To make implementation of this model effective, the selected literary works should be works whose content could trigger debates among students. An example of a good literary work would be the folklore of Southeast Sulawesi, called Larumbalangi. The learners can debate about the origin of the figures that are illustrated in the folklore.

The following steps are applicable for prompting debates on literary topics:

1. To make the debate process well organized and run well, the class is divided into two groups, namely the pro and contra groups. The pro group approves the attitude, behavior, and opinion of the main character, whereas the contra group rejects the attitude, behavior, and the opinion of the main character.

2. When the debate is completed under the guidance of the teacher, the students are asked to read the folklore which has been prepared by the teacher.

3. Each group is obliged to defend their opinion by arguing and presenting a variety of reasons to support their opinion.

Teachers should remember that the opinion of each group (both pro and contra groups) should be formulated clearly by teachers to facilitate the students' search for the reasons contained in literary works which are being debated. Again, the time allocated for the debate should be adequate so that each group (both pro group and contra group) can present their arguments completely. Here is an example:

1. Read another folklore of Southeast Sulawesi entitled Konggaaha.

2. Identify the attitudes, actions, and the opinions of the main character.

3. The pro group looks for the reasons why they agree with the attitudes, actions, and the opinion of the main character. Conversely, the contra group looks for the reason why they refuse or disagree with the attitudes, actions, and actors' statement.

4. After that, start arguing about the attitudes, actions, and the opinion of the main character in the folklore of Southeast Sulawesi Konggaaha, guided by the teacher.
An alternative activity would be:

1. The teacher reads a story to the students.

2. While listening to the story read by the teacher, the students note the main points of the story, especially the attitudes, actions, and the opinion of the main character.

3. The story read by the teacher is not too long, but it still reflects the integrity of the story.

4. The teacher tells the students (pro or contra groups) to give a reason for each argument they present.

5. After that, the pro and contra groups debate under the teacher guide.

These activities enable the learner to manipulate grammar, phonology, semantic, and pragmatics of the language they are learning. Pedagogically, this paper focuses on a verbal-linguistic-based learning model. It has been pointed out that this instructional model tries to offer a design with attention to five components and presents examples of verbal-linguistic intelligence-based learning activities by extending the examples drawn from cultural events occurring in the district of Kolaka, Southeast Sulawesi Province. The learning model described earlier is a learning model based on verbal-linguistic intelligence by presenting five components namely, (1) definition, (2) characteristics, (3) teaching strategy (4) best final learning outcomes, and (5) characters. Of the five components described, the second and the third components namely characteristics and the best final learning outcomes are considered appropriate. In the characteristic component, the author tries to maximize the verbal-linguistic intelligence of the children in order to display the skills and language skills they have. In the final learning outcome component, several professions and scientific backgrounds are shown with the consideration that the professions will motivate the children in their choice.

\section{CONCLUSION}

Learning-based models of verbal-linguistic intelligence can be designed with attention to five components namely (1) definition, (2) characteristics, (3) learning strategy (4) best final learning outcomes, and (5) figures. The five components are related to each other. Verbal-linguistic intelligence is the ability to use words effectively, both orally and in writing. This intelligence includes sensitivity to the meaning of words, the order of words, sounds, rhythm and intonation of the spoken word, the ability to understand the power of words to change the state of mind and convey information. The core components of verbal-linguistic intelligence, covering skill of manipulating grammar, phonology, semantics, and pragmatics. To stimulate the intellect of a child using verbal language, we can invite children to converse, read stories/fables, and teach them to sing a song.

There are several models of educational verbal-linguistic intelligence that can be developed through the study of literature. They involve activities such as arguing, discussing, interpreting, submitting reports, talking, and writing about literary works. In short, learning-based models of verbal-linguistic intelligence can be designed with attention to five components which are linked to each other, namely defi- 
nition, characteristics, learning strategy, best final learning out-comes, and figures.

This paper presents ideas for future researchers in both theoretical and practical perspectives. From a theoretical perspective, the verbal-linguistic intelligence-based learning design model should be continuously developed so that we could produce verbal-linguistic intelligence-based learning designs that are suitable with the demands of progresses in science. Research on verbal-linguistic intelligence-based learning design is still very limited and more detailed, comprehensive, and deeper studies are necessary in this area.

In order to improve the success of language teaching programs in schools as well as colleges, lecturers and teachers should constantly update learning models, especially verbal-linguistic learning model inspired from local cultures.

\section{REFERENCES}

Armstrong, T. (1996). Multiple Intellegancas in the Classroom. Virginia: Assosiation for Supervision and Currikulum Development.

Armstrong, T. (1993). 7 Kinds of Smart: Identifying and Development Your Intellegences. New York: Penguin Group.

Gardner, H. (2003). Creators: Multiple intelligences. In B. Adolphe (Ed.), The origins of creativity (pp. 117-145). Oxford: Oxford University Press.
Gardner, H. (1999). Intelligence Reframed: Multiple Intelligences for the $21^{\text {st }}$ Century. NewYork: Basic Books.

Gardner, H. (1993). Multiple Intellegences: The Theory in Practice A Reader. New York: Basic Books.

Hawkins, J. \& Blakeslee, S. (2002). On Intelligence. Jakarta: Dunia Pustaka Jaya.

Kwok-Cheung, Cheung. (2009). Reforming Teaching and Learning Using Theory of Multiple Intelligences: The Macao Experiences. Springer Science (online book): Business Media B.V.

Lane, C. (2009). Implementing Multiple Intelligences and Learning Styles in Distributed Learning/MS Projects. [Online] Available: (http://www.tecweb.org/styles/ imslsindl.pdf). (April 21, 2017)

McKenzie, W. (2005). Multiple Intelligences and Instructional Technology. Washington: International Society for Technology in Education.

Sonawat, R. \& Gogri, P. (2008). Multiple Intelligences for Pre-school Children. Mumbai: Multi-Tech Publishing Co.

van der Putten, J. (2010). Bongkar Bahasa: Meninjau Kembali Konsep yang Beraneka Makna dan Beragam Fungsi (Dibukukan oleh editor: Mikihiro Moriyama dan Manneke Budiman dalam Geliat Bahasa Selaras Zaman. Perubahan Bahasa-Bahasa di Indonesia Pasca Orde Baru. Jakarta: KPG. 